\title{
The role of RAS oncogene in survival of patients with lung cancer: a systematic review of the literature with meta-analysis
}

\author{
C Mascaux ${ }^{*, 1,7}, \mathbf{N}$ lannino', B Martin', M Paesmans ${ }^{2}$, T Berghmans', M Dusart ${ }^{3}$, A Haller $^{4}$, P Lothaire $^{5}$, \\ A-P Meert ${ }^{1,7}$, S Noel', J-J Lafitte ${ }^{6}$ and J-P Sculier'
}

'Department of Intensive Care and Thoracic Oncology, Institut Jules Bordet, Centre des Tumeurs de I'Université Libre de Bruxelles, Belgium; ${ }^{2}$ Data Centre, Institut Jules Bordet, Centre des Tumeurs de l'Université Libre de Bruxelles, Belgium; ' ${ }^{3}$ Department of Nuclear Medicine, Institut Jules Bordet, Centre des Tumeurs de l'Université Libre de Bruxelles, Belgium; ${ }^{4}$ Department of Pathology, Institut Jules Bordet, Centre des Tumeurs de l'Université Libre de Bruxelles, Belgium; ${ }^{5}$ Department of Surgery, Institut Jules Bordet, Centre des Tumeurs de l'Université Libre de Bruxelles, Belgium; ${ }^{6}$ Chest Department, CHU Calmette, Lille, France; ' ${ }^{7}$ NNRS (Fonds National de la Recherche Scientifique), Belgium

\begin{abstract}
The proto-oncogene RAS, coding for a $21 \mathrm{kDa}$ protein (p2 I), is mutated in $20 \%$ of lung cancer. However, the literature remains controversial on its prognostic significance for survival in lung cancer. We performed a systematic review of the literature with metaanalysis to assess its possible prognostic value on survival. Published studies on lung cancer assessing prognostic value of RAS mutation or p2l overexpression on survival were identified by an electronic search. After a methodological assessment, we estimated individual hazard ratios (HR) estimating RAS protein alteration or RAS mutation effect on survival and combined them using metaanalytic methods. In total, 53 studies were found eligible, with 10 concerning the same cohorts of patients. Among the 43 remaining studies, the revelation method was immunohistochemistry $(\mathrm{HC})$ in nine and polymerase chain reaction (PCR) in 34. Results in terms of survival were significantly pejorative, significantly favourable, not significant and not conclusive in 9, I, 3I, 2, respectively. In total, 29 studies were evaluable for meta-analysis but we aggregated only the 28 dealing with non-small-cell lung cancer (NSCLC) and not the only one dealing with small-cell-lung cancer (SCLC). The quality scores were not statistically significantly different between studies with or without significant results in terms of survival, allowing us to perform a quantitative aggregation. The combined HR was I.35 (95\% Cl: 1.16-1.56), showing a worse survival for NSCLC with KRAS2 mutations or p2I overexpression and, particularly, in adenocarcinomas (ADC) (HR I.59; 95\% Cl I.26-2.02) and in studies using PCR (HR I.40; 95\% Cl I.l8- I.65) but not in studies using $\mathrm{IHC}$ (HR I.08; 95\% Cl 0.86-1.34). RAS appears to be a pejorative prognostic factor in terms of survival in NSCLC globally, in ADC and when it is studied by PCR.
\end{abstract}

British Journal of Cancer (2005) 92, I 3 I - 139. doi: I0.1038/sj.bjc.6602258 www.bjcancer.com

Published online 14 December 2004

(c) 2005 Cancer Research UK

Keywords: RAS; p21; lung cancer; meta-analysis; systematic review; survival; prognostic factor

Lung cancer is a major cause of death despite diagnostic and therapeutic improvements. The overall 5-year survival rate is less than $10 \%$. However, the prognosis can be modulated by characteristics related to the patient or to the tumour. Some independent prognostic factors for survival have already been identified. They include, for small-cell lung cancer (SCLC): disease extent and performance status (PS) (Paesmans et al, 2000); for non-small cell lung cancer (NSCLC): PS, stage and, with lower impact, age, sex and weight loss (Paesmans et al, 1995; Strauss, 1997).

With the recent progresses in molecular biology, the research on prognostic factors could be extended to proteins and genes involved in cancer development. The biological factors implicated in carcinogenesis should also be considered as potential survival prognostic factors. Some of them, like angiogenesis and factors

*Correspondence: Dr C Mascaux, Institut Jules Bordet, rue HégerBordet, I B- 1000 Brussels, Belgium; E-mail: celine.mascaux@bordet.be Received 18 June 2004; revised 29 September 2004; accepted 18 October 2004; published online 14 December 2004 reflecting proliferative state, have already been identified in patients with lung cancer (Kanters et al, 1995). In order to clarify the prognostic impact of other biological factors in lung cancer, our group has performed systematic reviews of the literature with meta-analyses. It allowed us to show that VEGF (Delmotte et al, 2002), microvessel density (Meert et al, 2002b), c-erbB-2 (Meert et al, 2003) and p53 (Steels et al, 2001) have statistically significant worse impact on survival, while Bcl-2 (Martin et al, 2003) has a favourable survival impact.

Oncogenes (RAS, Raf, Myc, Src, Abl/Bcr, c-erbB-2, ...) are derived from normal genes (the proto-oncogene) coding for proteins, which play key roles in physiological cellular processes such as regulations of gene expression or growth signal transduction. Particularly, RAS oncogene is involved in lung cancer development. Three human RAS genes (Rodenhuis and Slebos, 1990) have been identified: the HRAS gene (homologous to the oncogene of the Harvey rat sarcoma virus), the KRAS2 gene (homologous to the oncogene of the Kirsten rat sarcoma virus) and the NRAS gene (first isolated from a human neuroblastoma). These genes code for four highly homologous $21 \mathrm{kDa}$ proteins called p21, with a common effector domain within the $\mathrm{N}$-terminal 
region. To be biologically active, RAS proteins must be localised to the inner face of the plasma membrane, where they can effectively interact with their upstream activators and downstream targets. The RAS gene proteins can exist in two states: an active state, in which GTP is bound to the molecule and an inactive state, in which the GTP has been hydrolysed to GDP. In physiologic conditions, the active isoform initiates cell proliferation through the RASdependent kinase cascade. The RAS proteins possess intrinsic GTPase activity, which normally leads to their inactivation and the control of cell growth. In tumours, a point mutation resulting in loss of the intrinsic GTPase activity appears to be associated with transforming activity of the protein, which does not stop anymore to send the signal stimulating cell proliferation. KRAS2 mutations are particularly common in pancreatic cancers, colorectal malignancies and lung cancer (Rodenhuis, 1992; Minamoto et al, 2000).

RAS mutations are detected in $15-20 \%$ of NSCLC and, particularly, $30-50 \%$ of adenocarcinomas (ADC) (Rodenhuis et al, 1988). In lung cancer, $90 \%$ of the mutations are located in the RAS2 gene and both NRAS mutations and HRAS mutations have occasionally been documented (Rodenhuis and Slebos, 1990). In total, $80 \%$ of KRAS2 mutations occur in codon 12 . Other mutations are located in codons 13 and 61. The predominant mutation is a G-T transversion (70\% of tumours) (Rodenhuis and Slebos, 1990).

The literature remains controversed on the prognostic value of RAS for survival in patients with lung cancer. In order to clarify this question, we have performed a systematic review of the literature with methodological assessment and meta-analysis.

\section{MATERIALS AND METHODS}

\section{Publications selection}

To be eligible for the systematic review, a study had to fulfil the following criteria: to deal only with lung cancer (any stage or histology), to assess the correlation between RAS mutation or p21 expression and survival, to analyse RAS-p21 in the primary tumour (not in metastatic tissue or tissue adjacent to the tumour) and/or antibodies against p21 in the serum, to have been published as a full paper in the English or French language. Abstracts were excluded because they do not provide sufficient data to evaluate the methodological quality of the trial and/or to perform metaanalysis.

Studies were identified by an electronic search on Medline databank and using the following keywords: 'lung cancer', 'lung carcinoma', 'lung neoplasms', 'lung tumour', 'lung tumours', 'lung tumour', 'lung tumours', 'lung adenocarcinoma', 'lung squamous', 'NSCLC', 'non-small cell lung cancer', 'non small cell lung cancer', 'non-small cell lung carcinoma', 'non small cell lung carcinoma', 'SCLC', 'small cell lung cancer', 'small cell lung carcinoma', 'ras', 'K-ras', 'Ki-ras', 'n-ras', 'c-ras', 'l-ras', 'h-ras', 'p21'. The search ended on July 2003. The bibliographies reported in all the identified studies were used to complete this search. When the authors reported results obviously obtained on the same patients population in several publications, only the most recent or the most complete study was included in the analysis, in order to avoid overlapping between cohorts.

\section{Methodological assessment}

To assess the quality of the methodology, each study was read independently by 12 investigators, including nine physicians and three scientists. The participation of many readers was a guarantee for the correct interpretation of the articles. The methodological evaluation was scored according to the European Lung Cancer Working Party (ELCWP) scale. The scoring system used has already been described in one of our prior systematic reviews
(Steels et al, 2001). Each item was assessed using an ordinal scale (possible values: 2, 1, 0). A consensus was reached in regular meetings where at least two-thirds of the investigators needed to be present. As the assessed items were objective ones, a consensus was always obtained.

The overall score evaluated several dimensions of the methodology, grouped into four main categories: the scientific design, the description of laboratory methods used to identify the presence of RAS mutation or p21 expression, the generalisability of the results and the analysis of the study data. Each category had a maximum score of 10 points, with a maximal theoretical score of 40 points. When an item was not applicable to a study, its value was not taken into account in the total of the concerned category. The final scores were expressed as percentages, ranging from 0 to $100 \%$, higher values reflecting better methodological quality. Studies included in the systematic review were called 'eligible', those providing sufficient data for the meta-analysis 'evaluable'. To be eligible, studies had to provide univariate analysis.

\section{Statistical methods}

A study was considered as significant if the $P$-value for the statistical test comparing survival distributions between the groups with and without RAS-p21 alteration was $<0.05$. A study was called 'positive' when a mutation/expression in RAS-p21 protooncogene was identified as a significant favourable prognostic factor for survival. The study was called 'negative' if the same characteristic was associated with a significant detrimental impact on survival. Finally, a study was called 'not significant' if no statistically significant difference between the two groups was detected and 'not conclusive' if any conclusion about significance of survival results could be derived from the article.

The association between two continuous variables was measured by the Spearman rank correlation coefficient. Nonparametric tests were used to compare the distribution of the quality scores according to the value of a discrete variable (Mann-Whitney tests for dichotomic variables or Kruskal-Wallis tests for multiple classes variables).

For the quantitative aggregation of the survival results, we measured the impact of RAS mutation and/or p21 expression on survival by hazard ratio (HR) between the two survival distributions. For each trial, this HR was estimated by a method depending on the data provided in the publication. The most accurate method consisted of calculating the estimated HR and its standard error (s.e.) from the reported results or to calculate them directly using two of the following parameters: the O-E statistic (difference between numbers of observed and expected events), the confidence interval (CI) for the HR, the logrank statistic or its $P$-value. If these were not available, the total number of events, the number of patients at risk in each group and the logrank statistic or its $P$ value were used to allow for an approximation of the HR estimate. Finally, if the only exploitable data were in form of graphical representations of the survival distributions, survival rates at some specified times were extracted in order to reconstruct the HR estimate and its variance, with the assumption that the rate of patients censored was constant during the study follow-up (Parmar et al, 1998). If this last method was used, three independent persons read the curves to reduce inaccuracy in the extracted survival rates. The individual $H R$ estimates were combined into an overall HR using Peto's method (Yusuf et al, 1985), which consisted of using a fixed effect model assuming homogeneity of the individual true HRs. This assumption was tested by performing $\chi^{2}$ tests for heterogeneity. If the assumption of homogeneity had to be rejected, we used a random-effect model as a second analysis. By convention, an observed $\mathrm{HR}<1$ implied a better survival for the group with mutated RAS or p21 expression. This impact of RAS on survival was considered as statistically 
significant if the $95 \%$ confidence interval for the overall HR did not overlap 1.

When data about global survival of the entire patients population were available, survival was analysed globally. If authors only reported the results separately for different subgroups, those results corresponded to different cohorts of patients and were treated separately in the meta-analysis.

\section{RESULTS}

\section{Study selection and characteristics}

In total, 53 publications, published between 1990 and 2003, were found eligible for the systematic review (Rodenhuis et al, 1988, 1997; Slebos et al, 1990; Mitsudomi et al, 1991; Miyamoto et al, 1991; Harada et al, 1992; Sugio et al, 1992; Rosell et al, 1993, 1995b, 1996, 1997; Volm et al, 1993, 2002; Westra et al, 1993; Kern et al, 1994; Li et al, 1994; Silini et al, 1994; Fujino et al, 1995; Kashii et al, 1995; Keohavong et al, 1996, 1997; Cho et al, 1997; Dosaka-Akita et al, 1997; Fukuyama et al, 1997; Komiya et al, 1997; Pifarré et al, 1997; Siegfried et al, 1997; Visscher et al, 1997; De Gregorio et al, 1998; Greatens et al, 1998; Huang et al, 1998; Kim et al, 1998; Kwiatkowski et al, 1998; Nemunaitis et al, 1998; Wang et al, 1998; Dingemans et al, 1999; Fu et al, 1999; Graziano et al, 1999; Miyake et al, 1999; Nelson et al, 1999; Hommura et al, 2000; Konishi et al, 2000; Moldvay et al, 2000; Schneider et al, 2000; Andjelic et al, 2001; Kang et al, 2001; Schiller et al, 2001; Ahrendt et al, 2002; Broermann et al, 2002; Shoji et al, 2002; Tomizawa et al, 2002; Grossi et al, 2003; Ramirez et al, 2003). In all, 10 of these articles were excluded because an identical patient cohort had been used in other selected publications (Rodenhuis et al, 1988; Miyamoto et al, 1991; Fujino et al, 1995; Rosell et al, 1995a, b, 1996; Dosaka et al, 1997; Keohavong et al, 1997; Hommura et al, 2000; Konishi et al, 2000; Volm et al, 2002). One of the 43 remaining studies (Volm et al, 1993) assessed separately by immunohistochemistry (IHC) KRAS2, NRAS and HRAS p21. All the other papers concerned KRAS2 only. Therefore, for the meta-analysis, we took into account only the characteristics and the data concerning KRAS2 p21 expression.

The total number of included patients was 5216, ranging from 21 to 355 patients per study (median: 103). The main characteristics of the 43 publications eligible for the systematic review are reported in Table 1 . In total, 27 were dealing with NSCLC, 11 with adenocarcinoma only, three with any histological type, one with SCLC and one with both ADC and large cell carcinoma. A total of 22 studies concerned only nonmetastatic disease, one only stage IV disease and 19 all stages (I-IV). One study did not mention the stage of the tumours. In 15 publications, patients were treated by surgery alone. Surgery was associated with an adjuvant therapy (radiotherapy and/or chemotherapy) in 26. In one study, SCLC patients were treated with a combination of radiotherapy and chemotherapy (Dingemans et al, 1999). In the last paper, treatment was not described De Gregorio et al, 1998).

Nine studies evaluated the accumulation of 21 protein by IHC. The other 34 identified RAS mutation by molecular biology, using different polymerase chain reaction (PCR) methodologies, mainly, single-strand conformation polymorphism (SSCP) $(n=10)$ and restriction fragment length polymorphism (RFLP) $(n=8)$.

Among the 43 studies eligible for the systematic review, 14 were inevaluable for the meta-analysis due to insufficient data reported in the article. The reasons for noninclusion of a study into the meta-analysis were the lack of available survival results to calculate HR in 13 (Volm et al, 1993; Westra et al, 1993; Li et al, 1994; Kashii et al, 1995; Pifarré et al, 1997; Visscher et al, 1997; De Gregorio et al, 1998; Greatens et al, 1998; Fu et al, 1999; Miyake et al, 1999; Schneider et al, 2000; Andjelic et al, 2001; Broermann et al, 2002) and the lack of repartition of tumours according to RAS mutation/ expression in 1 (Ahrendt et al, 2002).

\section{Study results report}

Nine of the 43 studies (20.9\%) identified proto-oncogene RAS mutations or $\mathrm{p} 21$ overexpression as a pejorative prognostic factor for survival (with seven evaluable for the meta-analysis), 31 (72.1\%) concluded that RAS was not a prognostic factor for survival (21 evaluable), one (2.3\%) reported a better prognosis for RAS positivity (evaluable) and two $(4.7 \%)$ were nonconclusive (both nonevaluable).

Overall, the rates of RAS mutations detected by PCR and p21 protein overexpression were, respectively, 18.4\% (number of evaluable tumours $(n)=3779)$ and $44.6 \%(n=1548)$ in NSCLC, $7.1 \%(n=141)$ and $32.3 \%(n=223)$ in squamous cell carcinomas (SQCC) and $23.1 \%(n=1847)$ and $34.7 \%(n=222)$ in ADC. The rates of positive tumours by molecular biology or IHC were, respectively, $21.8 \%(n=1015)$ and $54.8 \%(n=135)$ in stage I NSCLC, $16.0 \%(n=399)$ and $53.5 \%(n=71)$ in NSCLC patients with stages I and II, $16.2 \%(n=1263)$ and $38.5 \%(n=929)$ in those with stages I-III.

\section{Quality assessment}

The overall quality score ranged from 31.04 to $78.15 \%$ with a median of $52.2 \%$ (Table $2 \mathrm{~A}$ ). The design subscore had the lowest value, with a median of $40 \%$.

No statistically significant quality difference was shown between significant and nonsignificant studies neither for the global score (median: 51.50 vs $53.83 \%, P=0.90$ ), neither for the four subgroups scores. There was also no statistically significant difference between evaluable and nonevaluable studies for meta-analysis in terms of global scores ( 55.23 vs $44.31 \%, P=0.10)$, but the evaluable ones had a better score concerning the report of the analysis results: $62.5 \%$ in comparison to $31.3 \%$ for the nonevaluable trials $(P=0.001)$. There was a significant correlation between the global score and the number of patients included (Spearman correlation coefficient $r=0.50, P=0.0006$ ), studies including a higher number of patients showing a better global score. The generalisability of the results was significantly better in the recent publications ( $r=0.42, P=0.004)$. There was also a statistically significant difference between studies assessing RAS-p21 status by IHC $(n=9)$ or by molecular biology $(n=34)$, with global scores of 58.51 and $49.93 \%$, respectively $(P=0.029)$ and scores assessing the description of the laboratory methodology of 64.3 vs $46 \%$, those based on IHC being better described than those on molecular biology $(P=0.002)$.

Table $2 \mathrm{~B}$ reports the analysis of the scores for the 29 studies evaluable for meta-analysis. Their overall quality score ranged between 34.25 and $78.15 \%$, with a median of $55.24 \%$. The design subscore was also the worst reported. Like previously observed among eligible publications, there was no statistically significant difference between significant and nonsignificant studies evaluable for the meta-analysis according to the global score (median of 53.04 vs $53.42 \%, P=0.92$ ). There was also a significant correlation between global score and the number of patients included in the study (Spearman correlation coefficient $r=0.53, P=0.006$ ) and those assessing RAS positivity by IHC obtained a better quality scores for the laboratory method subgroup (57.1 vs $50 \%$ for molecular biology, $P=0.04$ ), but not for the global score.

\section{Meta-analysis}

The absence of significant methodological quality difference between significant and nonsignificant studies allowed us to perform a quantitative aggregation of the survival results. The 
Table I Main characteristics and results of the eligible studies

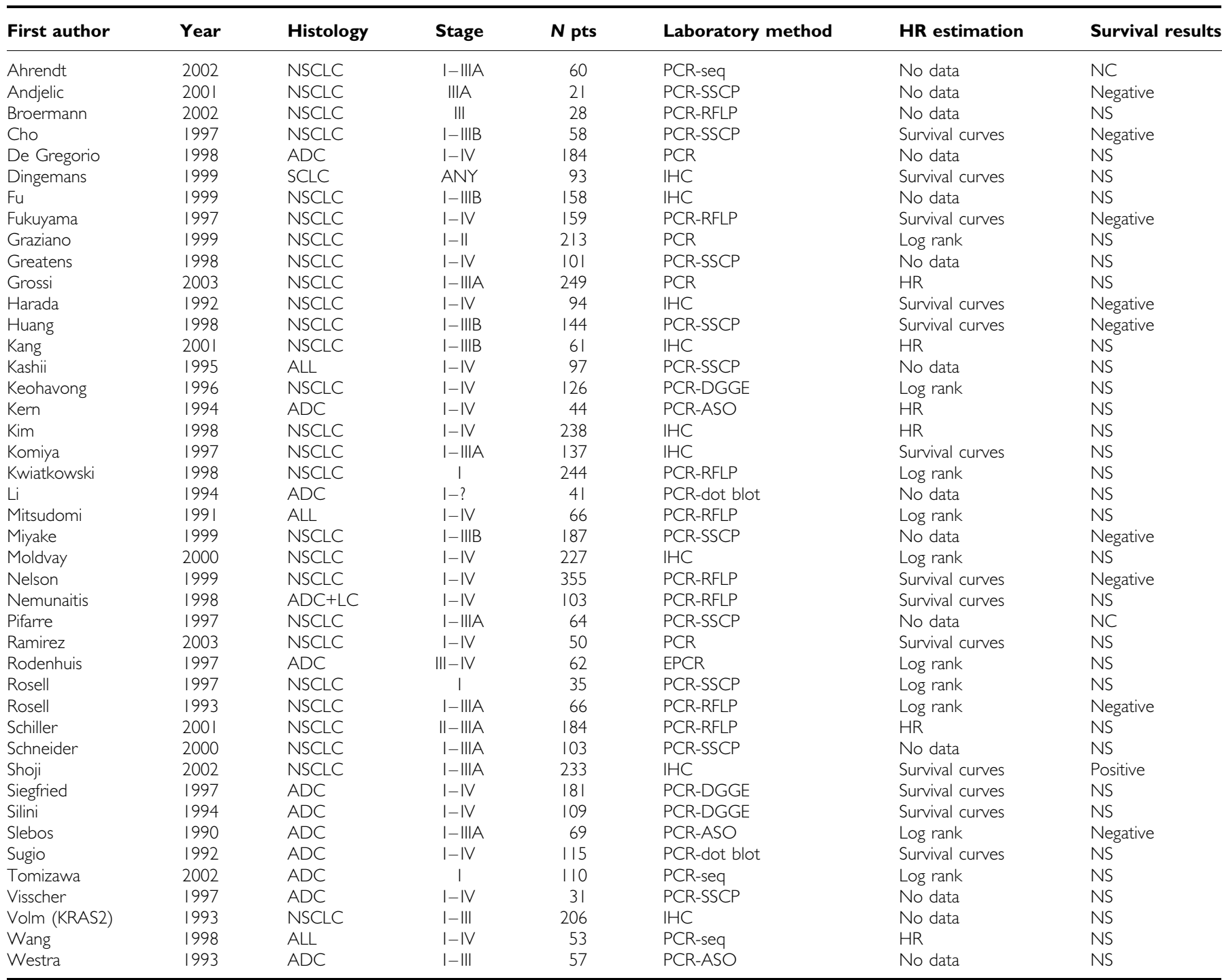

$N$ pts = number of patients; $H R=$ hazard ratio; NSCLC=non-small-cell lung cancer; $A D C=$ adenocarcinoma; $S C L C=$ small-cell lung carcinoma; $L C=$ large cell; $\mathrm{NC}=$ nonconclusive; $\mathrm{NS}=$ nonsignificative; $\mathrm{PCR}=$ polymerase chain reaction; $\mathrm{SSCP}=$ single-strand conformation polymorphism; RFLP = restriction fragment length polymorphism; $\mathrm{ASO}=$ allele-specific oligonucleotide hybridisation; DGGE = denaturating gradient gel electrophoresis; seq = PCR followed by sequencing of olignucleotide; $E P C R=$ mutant-enriched PCR; $I H C=$ immunohistochemistry; HR estimation = description of the methods used to estimate the individual HR according the three corresponding of the three different methods described in the statistics paragraph.

meta-analysis was performed on 28 studies (3620 patients) dealing with NSCLC.

The individual HR of the 28 aggregable studies were calculated by one of the three methods reported in the Materials and Methods section according to the available data. Only six studies reported the data needed to directly calculate the estimated HR (HRs and $95 \%$ confidence intervals). In 10 trials, HR was approximated by the total number of events and the logrank statistic. For the 12 remaining studies, HR had to be extrapolated from the graphical representation of the survival distributions.

The NSCLC overall meta-analysis included the 28 aggregable studies with a total number of 3620 patients. Two trials (Fukuyama et al, 1997; Moldvay et al, 2000) gave only subgroup survival analysis and their data were analysed separately like reported by authors, increasing the number of individual cohorts aggregated to 30. The aggregation of the survival data is described in Table 3. Overall RAS mutation or p21 expression was associated with a worse survival (HR (fixed effect model) 1.30; 95\% confidence intervals (CI) $1.20-1.49)$. The test of heterogeneity was significant $(P=0.01)$. Nevertheless, we calculated the HR by a random effect model that showed also a statistically significant impact on survival with an HR of 1.35 (95\% CI: 1.16-1.56).

In the subgroup analysis (Table 3 ) according to histology, RAS/ p21 was not a statistically significant prognostic factor for survival in SQCC (H: 1.49 , CI 95\%: $0.88-2.52$ ), but well in ADC, with heterogeneity between the trials (heterogeneity test: $P=0.02$ ) and a random effect HR of 1.59 (CI 95\%: 1.26-2.02). The meta-analysis of studies into three subgroups according to stages (stage I, stage I-III and stage I-IV) did not show any statistically significant impact of RAS on survival. For the last subgroup (stage I-IV) there were 11 studies with a large heterogeneity $(P<0.001)$ and the random effect HR was borderline (1.41, 95\% CI: 0.99-1.99).

Furthermore, we aggregated the studies separately according to the method used to detect RAS/p21 alteration (Table 3). The studies were first divided into two main groups according to the laboratory method: IHC (Figure 1) or molecular biology (Figure 2), 
Table 2 Results of the methodological assessment of (a) eligible studies by the European Lung Cancer Working Party score and (b) evaluable studies by the European Lung Cancer Working Party score

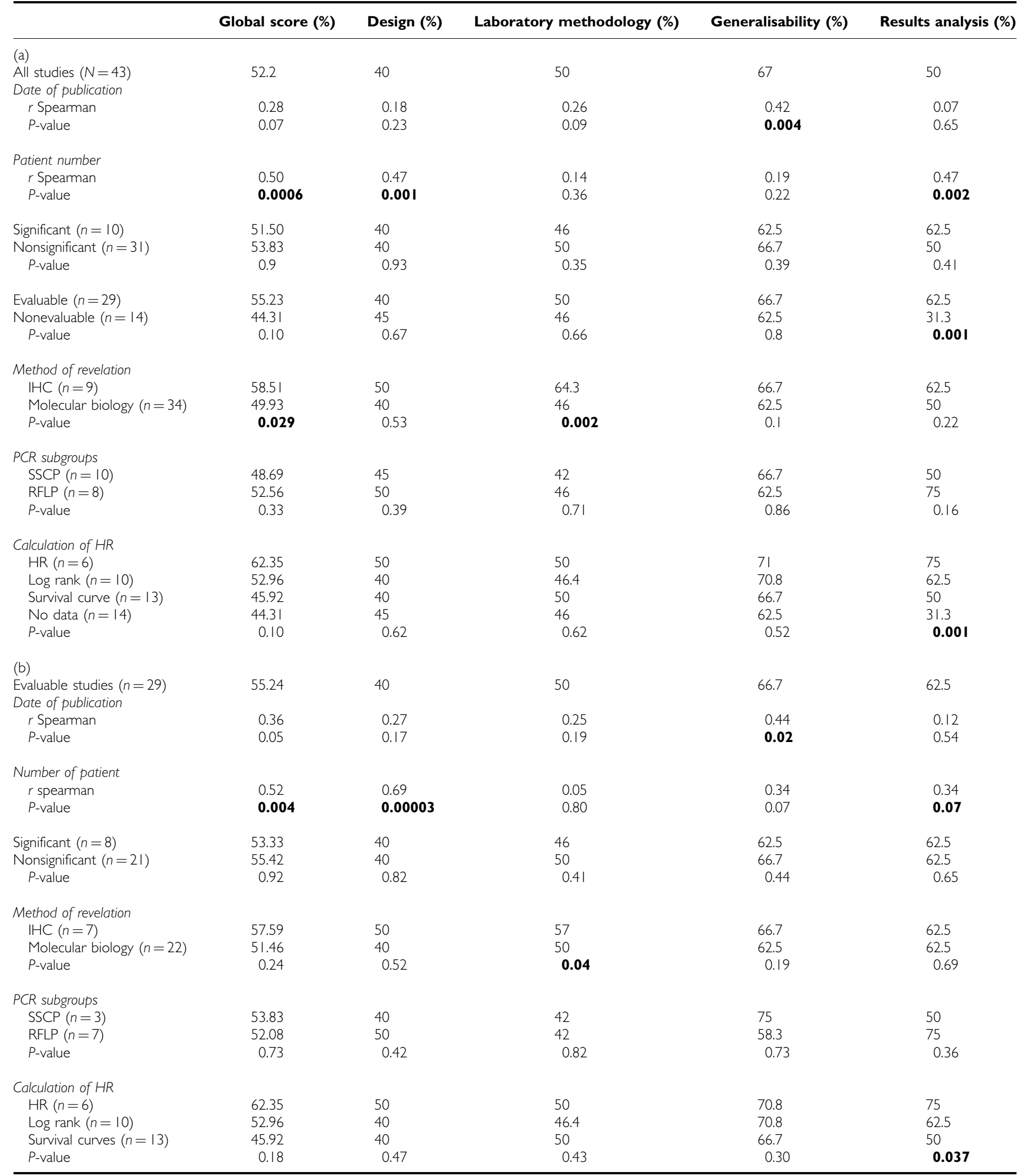

$r$ Spearman = correlation coefficient of Spearman; $\mathbb{H C}=$ immunohistochemistry; $\mathrm{PCR}=$ polymerase chain reaction; $\mathrm{SSCP}=$ single-strand conformation polymorphism; $\mathrm{RFLP}=$ restriction fragment length polymorphism; $\mathrm{HR}=$ hazard ratio. The $P$-values are in bold when the statistical test is significant. 
Table 3 Hazard ratio (HR) value for the NSCLC subgroup according to histology, stage and laboratory technique

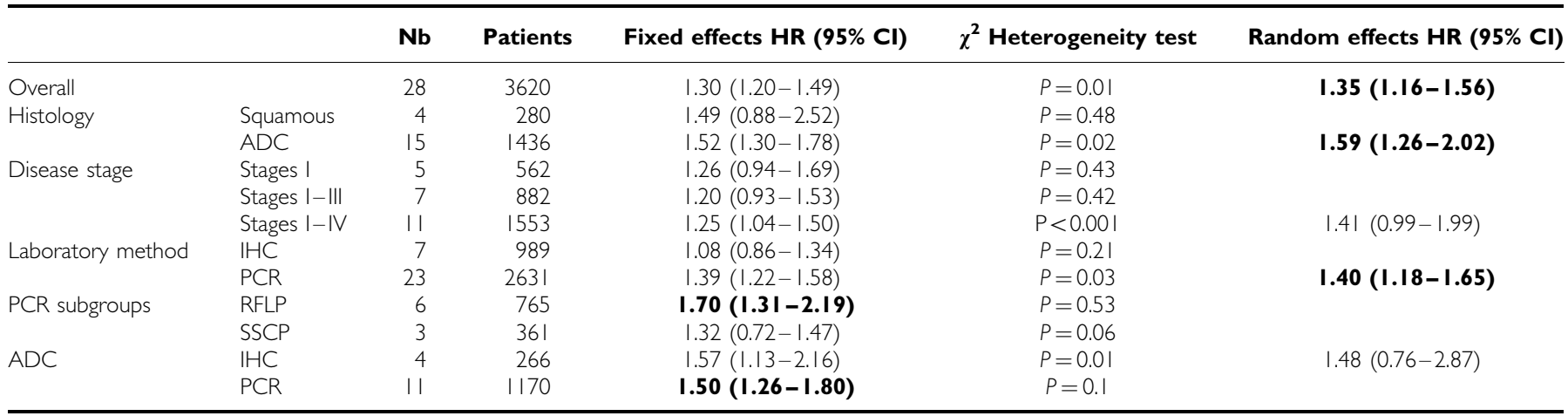

$\mathrm{Nb}=$ number of studies; $\mathrm{ADC}=$ adenocarcinomas; $\mathrm{HC}=$ immunohistochemistry; $\mathrm{PCR}=$ polymerase chain reaction; $\mathrm{SSCP}=$ single-strand conformation polymorphism; RFLP = restriction fragment length polymorphism; statistically significant results are in bold.

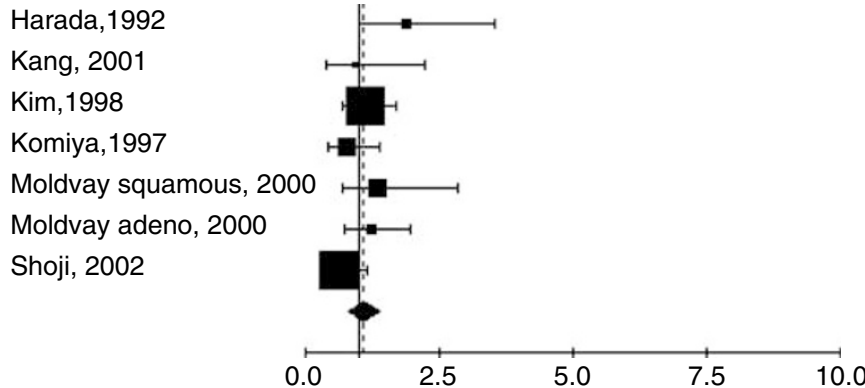

Figure I Meta-analysis of studies assessing RAS with $I H C$ in NSCLC. Hazard ratio (HR) and $95 \%$ confidence interval $(\mathrm{Cl})$ of survival in studies evaluating RAS-p2 I status in NSCLC. HR> I implies a survival disadvantage for the group with $\mathrm{p} 2 \mathrm{I}$ expression. The square size is proportional to the number of patients included in the study. The center of the lozenge gives the combined HR of the meta-analysis and its extremities the $95 \%$ confidence interval. $\mathrm{HR}=1.08 ; \mathrm{Cl} 95 \% 0.86-1.34$. Total number of patients: 989.

including the different techniques of PCR. The fixed effect HR were respectively 1.08 (95\% CI: $0.86-1.34)$ and 1.39 (95\% CI: $1.22-1.58)$ for IHC and molecular biology. For PCR, there was a statistically significant heterogeneity $(P=0.03)$ and the random effect HR was 1.40 (95\% CI: $1.18-1.65)$. Among the studies with PCR based revelation technique, two methods, PCR-RFLP and PCR-SSCP, were used in respectively six and three studies. Fixed effect HR of 1.7 (95\% CI: $1.31-2.19)$ and 1.32 (95\% CI: $0.72-1.47)$ were obtained, respectively, the first one only being statistically significant.

Finally, we decided to perform an analysis in histological subgroups separately according to the method of detection. There were only four studies dealing with SQCC and it was a nonsense to make more reduced subgroups analysis. We were able to analyse studies including ADC separating those using IHC from those applying PCR. Four studies were using IHC only. The HR (random-effects model, $\mathrm{p}$ heterogeneity test $=0.01$ ) was 1.48 (95\% CI 0.76-2.87). The HR (fixed-effects model, p heterogeneity test $=0.1)$ for 11 studies assessing RAS mutation by PCR in ADC was 1.50 (95\% CI 1.26-1.80) (Figure 3).

\section{DISCUSSION}

The present systematic review of the literature with meta-analysis shows that RAS gene alteration and/or protein $\mathrm{p} 21$ overexpression is a poor prognostic factor for survival of patients with NSCLC in univariate analysis. In subgroup analysis, the negative prognostic
Cho, 1997

Fukyama stages I-II,1997

Fukyama stages III-IV,1997

Graziano,1999

Grossi, 2003

Huang,1998

Keohavong,1996

Kern,1994

Kwiatkowski,1998

Mitsdudomi, 1991

Nelson, 1999

Nemunaitis, 1998

Ramirez, 2003

Rodenhuis, 1997

Rosell,1993

Rosell, 1997

Schiller, 2001

Siegfried, 1997

Silini, 1994

Slebos, 1990

Sugio, 1992

Tomizawa,2002

Wang, 1998

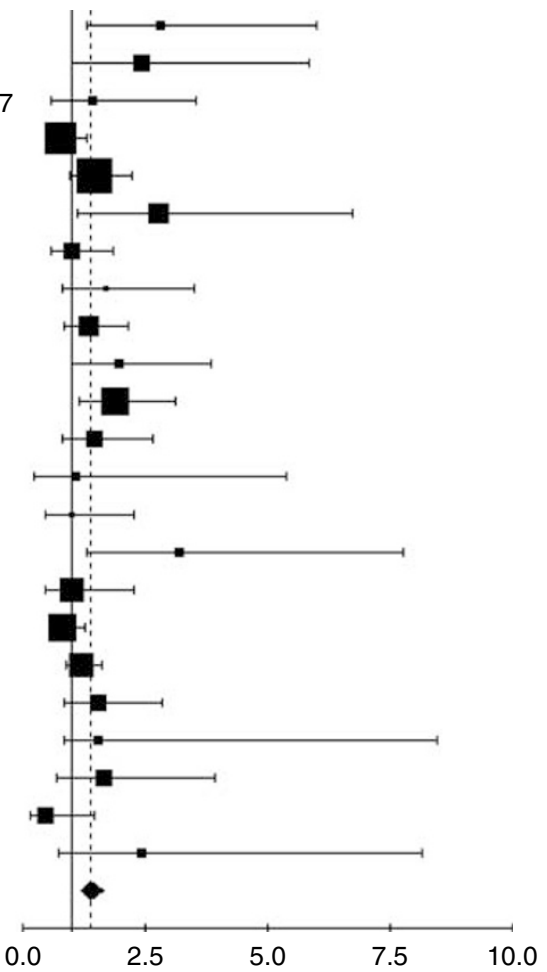

Figure 2 Meta-analysis of studies assessing RAS mutation with PCR in NSCLC. Hazard ratio (HR) and $95 \%$ confidence interval (Cl) of survival in studies evaluating RAS-p2 I status in NSCLC. HR> I implies a survival disadvantage for the group with RAS mutation. The square size is proportional to the number of patients included in the study. The centre of the lozenge gives the combined HR of the meta-analysis and its extremities the $95 \%$ confidence interval. $\mathrm{HR}=1.40 ; \mathrm{Cl} 95 \%$ I.18-1.65. Total number of patients: 2631 .

value of RAS alterations is observed in ADC but not for SQCC and when PCR is used as revelation method but not when IHC is used.

Our data help so to clarify the message of individual studies, arguing with the hypothesis that RAS is a prognostic factor for lung cancer. This still needs to be confirmed in prospective trials with appropriate multivariate analysis taking into account other clinical or biological prognostic factors. Another meta-analysis based on a review of the literature on the role of KRAS2 as prognostic factor in lung cancer was previously published (Huncharek et al, 1999). Only eight trials (Slebos et al, 1990; Kern et al, 1994; Silini et al, 1994; Rosell et al, 1995a; Cho et al, 1997; Fukuyama et al, 1997; Rodenhuis et al, 1997; Siegfried et al, 1997) 


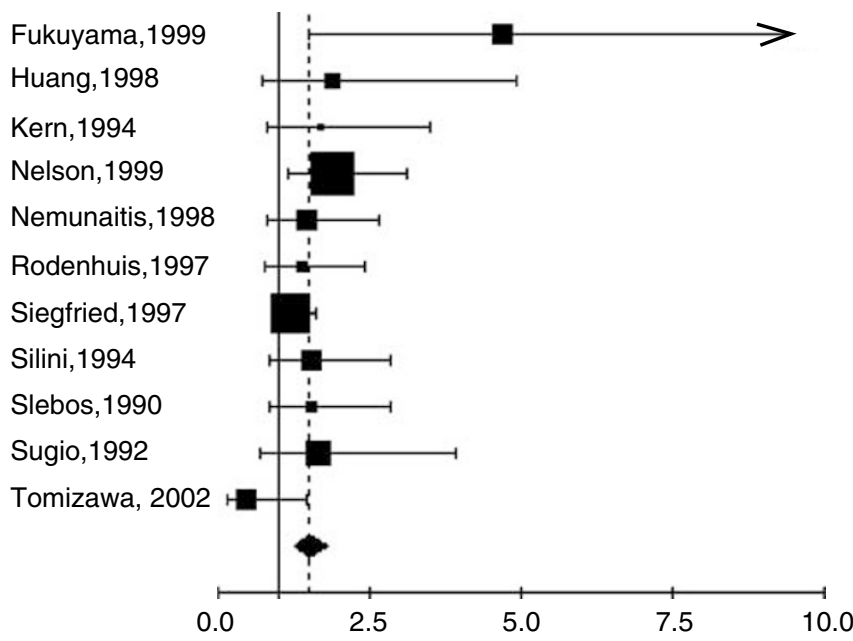

Figure 3 Meta-analysis of studies assessing RAS mutation by PCR in adenocarcinomas. Hazard ratio (HR) and $95 \%$ confidence interval $(\mathrm{Cl})$ of survival in studies evaluating RAS-p2 I status in NSCLC. HR $>$ I implies a survival disadvantage for the group with RAS mutation. The square size is proportional to the number of patients included in the study. The centre of the lozenge gives the combined HR of the meta-analysis and its extremities the $95 \%$ confidence interval. $\mathrm{HR}=1.50 ; \mathrm{Cl} 95 \%$ 1.26-1.80. Total number of patients: II 170.

were included because the selection criteria of the studies were different from ours: the search for studies ended in 1997, only trials documenting KRAS2 mutation by PCR (and not those with IHC) were included, other histologies than NSCLC were excluded, 2 -year survival rates had to be described. The authors observed that KRAS2 mutations detected by different PCR variants were poor prognostic factor for NSCLC. These results support the validity of ours. No subgroup analyses according to stage or histology (ADC vs SQCC) were performed, not allowing us to compare with our results.

RAS gene mutations are involved in oncogenesis of a variety of human tumours (Rodenhuis and Slebos, 1990). In lung cancer, Fisher et al (2001) has demonstrated that RAS mutation is necessary for induction and maintenance of lung cancer. The same author showed that lung tumours arising in the absence of tumour suppressor gene remain dependent on mutant KRAS2 for maintenance of tumour growth and that apoptosis after KRAS2 downregulation does not require p53 or Ink4A/Arf. Those points suggest that RAS plays a key role in lung carcinogenesis. Moreover, the present demonstration of its prognostic role in lung suggests that the detection of RAS alteration would also allow us to stratify patients with higher risk. It could also determine patients with a better chance to respond to specific treatment targeting RAS.

To avoid bias due to a more detailed reporting of significant trials, we decided to perform a methodological assessment of the publications prior to quantitative aggregation. We have used a methodology similar to previous systematic reviews reported by our group about biological prognostic factors in lung cancer (Steels et al, 2001; Delmotte et al, 2002; Meert et al, 2002a,b; Martin et al, 2003; Meert et al, 2003). The absence of a statistically significant difference in quality score between the significant and the nonsignificant publications allowed us to perform a quantitative aggregation (meta-analysis) of the results of the individual trials. However, this approach does not prevent all potential biases. Biases including publication bias, choice of language, selection of fully published studies only, method of extrapolation of HR, validity of a meta-analyses based on systematic review of the literature as compared with those based on individual data were already discussed in our previous papers (Steels et al, 2001; Delmotte et al, 2002; Meert et al, 2002a, b; Martin et al, 2003; Meert et al, 2003).
Some eligible trials had to be excluded from the meta-analysis because they did not provide sufficient data on survival. Among the 14 excluded studies, 12 were nonsignificant (86\%) while a lower proportion of the studies evaluable for the meta-analysis were nonsignificant (70\%). It is known that negative studies are less frequently published or, if they are, with less detailed results, making them less assessable. However, the methodological quality of trials, according to the global score, was not significantly different between evaluable and nonevaluable studies for the quantitative aggregation of individual survival results.

Some results need comments: we only demonstrated significant impact of RAS alterations in ADC and not in SQCC. This observation suggests that the biological signalling pathways implicated in carcinogenesis are different for ADC and for SQCC. Those information should interpreted carefully because RAS mutations are more frequently observed in ADC as compared with SQCC (23.12 vs 7.09\%) Moreover, authors more often assessed ADC rather than SQCC (1436 vs 280 patients in the meta-analysis). For example, Nelson's trial (Nelson et al, 1999), firstly based on all histological subtypes, did not detect any mutation in squamous cell carcinoma and thus did not report data on this histological subtype. Another example arises in Moldvay's study (Moldvay et al, 2000): she assessed overexpression of p21 by IHC in all tumours but only evaluate RAS mutation by PCR in ADC and not in SQCC. There is a potential bias to evalue the impact of RAS in squamous cell carcinomas and this should be further investigated.

The diversity in the techniques used to identify alteration of RAS-p21 status can also be a potential source of bias. Firstly, IHC is not comparable among the nine studies. There were six different primary antibodies, different revelation protocols and different level of positivity (from 0 to $50 \%$ or only based on intensity). Secondly, there is not a good correlation between DNA mutation and protein conformation or level of protein expression and thus between molecular biology and IHC. Authors (Nelson et al, 1999; Moldvay et al, 2000) who studied RAS mutation and p21 expression on the same tumours did not find any correlation between the two abnormalities. Particularly, Nelson (Nelson et al, 1999) did not observe significant impact of p21 expression in multivariate analysis $(P=0.89)$, but well for RAS mutation $(P=0.04)$. Moldvay (Moldvay et al, 2000) only found three patients among 81 analysed with both RAS IHC staining and KRAS2 point mutation. It could bring some potential explanations to the difference between IHC and PCR in our meta-analysis. PCR seems to be a more accurate technique to assess RAS in lung tumours. It is interesting to observe that we previously had never showed differences between the two techniques for other markers like p53 (Steels et al, 2001). This suggests the importance to determine the best method to assess each marker. There was also a difference between RFLP- and SSCP-PCR, only the first one showing statistically significant impact on survival of patient with lung cancer. There were only three trials with SSCP-PCR and the results reached to be significant. There is thus need to confirm or infirm those results prospectively with an adequately designed and powered trial. The PCR techniques used were thus different between the trials and between the specific KRAS2 codon analysed. Whatever, in the other meta-analysis (Huncharek et al, 1999), pooling all trials with PCR with an heterogeneity detected according to different procedure and codon analysed, the results reached significance. For clinical application, the best method to assess KRAS2 still needs to be determined in further studies to provide reproductible results and standardised evaluation.

In conclusion, our systematic review suggests that RAS mutation or p21 expression is of poor prognostic significance for survival in patients with non-small-cell lung cancer. The results were based on an aggregation of data obtained by univariate analysis in retrospective trials. In order to become a useful prognostic factor at the level of individual patients and in the context of targeted therapy, 
these results need to be confirmed by an adequately designed prospective study and the exact value of p21 expression needs to be determined by an appropriate multivariate analysis taking into account the classical well-defined prognostic factors for lung cancer. Moreover, molecular biology arises as a more accurate technique to assess RAS alteration as compared with IHC. It is a priority to confirm those data in order to determine the adequate method to assess RAS, which would then further allow performing prospective studies with adequate design and, particularly, adapted laboratory methods.

\section{REFERENCES}

Ahrendt SA, Yang SC, Wu L, Roig CM, Russell P, Westra WH, Jen J, Brock MV, Heitmiller RF, Sidransky D (2002) Molecular assessment of lymph nodes in patients with resected stage I non-small cell lung cancer: preliminary results of a prospective study. J Thorac Cardiovasc Surg 123: $466-473$

Andjelic G, Magic Z, Bokun R, Stepic V (2001) Mutations in K-Ras oncogene and their influence on survival of patients with non-small cell lung cancer. $J$ BUON 6: 61-66

Broermann P, Junker K, Brandt BH, Heinecke A, Freitag L, Klinke F, Berdel WE, Thomas M (2002) Trimodality treatment in Stage III nonsmall cell lung carcinoma: prognostic impact of $\mathrm{K}$-ras mutations after neoadjuvant therapy. Cancer 94: 2055-2062

Cho JY, Kim JH, Lee YH, Chung KY, Kim SK, Gong SJ, You NC, Chung HC, Roh JK, Kim BS (1997) Correlation between K-ras gene mutation and prognosis of patients with nonsmall cell lung carcinoma. Cancer 79: $462-467$

De Gregorio L, Manenti G, Incarbone M, Pilotti S, Pastorino U, Pierotti MA, Dragani TA (1998) Prognostic value of loss of heterozygosity and KRAS2 mutations in lung adenocarcinoma. Int J Cancer 79: 269-272

Delmotte P, Martin B, Paesmans M, Berghmans T, Mascaux C, Meert AP, Steels E, Verdebout JM, Lafitte JJ, Sculier JP (2002) VEGF and survival of patients with lung cancer: a systematic literature review and metaanalysis]. Rev Mal Respir 19: 577-584

Dingemans AM, Witlox MA, Stallaert RA, van der Valk P, Postmus PE, Giaccone G (1999) Expression of DNA topoisomerase IIalpha and topoisomerase IIbeta genes predicts survival and response to chemotherapy in patients with small cell lung cancer. Clin Cancer Res 5: $2048-2058$

Dosaka-Akita H, Hu SX, Fujino M, Harada M, Kinoshita I, Xu HJ, Kuzumaki N, Kawakami Y, Benedict WF (1997) Altered retinoblastoma protein expression in non-small cell lung cancer: its synergistic effects with altered ras and p53 protein status on prognosis. Cancer 79: $1329-1337$

Fisher GH, Wellen SL, Klimstra D, Lenczowski JM, Tichelaar JW, Lizak MJ, Whitsett JA, Koretsky A, Varmus HE (2001) Induction and apoptotic regression of lung adenocarcinomas by regulation of a K-Ras transgene in the presence and absence of tumor suppressor genes. Genes Dev 15: $3249-3262$

Fu XL, Zhu XZ, Shi DR, Xiu LZ, Wang LJ, Zhao S, Qian H, Lu HF, Xiang YB, Jiang GL (1999) Study of prognostic predictors for non-small cell lung cancer. Lung Cancer 23: 143 - 152

Fujino M, Dosaka-Akita H, Harada M, Hiroumi H, Kinoshita I, Akie K, Kawakami Y (1995) Prognostic significance of p53 and ras p21 expression in nonsmall cell lung cancer. Cancer 76: 2457-2463

Fukuyama Y, Mitsudomi T, Sugio K, Ishida T, Akazawa K, Sugimachi K (1997) K-ras and p53 mutations are an independent unfavourable prognostic indicator in patients with non-small-cell lung cancer. $\mathrm{Br}$ Cancer 75: 1125-1130

Graziano SL, Gamble GP, Newman NB, Abbott LZ, Rooney M, Mookherjee S, Lamb ML, Kohman LJ, Poiesz BJ (1999) Prognostic significance of Kras codon 12 mutations in patients with resected stage I and II nonsmall-cell lung cancer. J Clin Oncol 17: 668-675

Greatens TM, Niehans GA, Rubins JB, Jessurun J, Kratzke RA, Maddaus MA, Niewoehner DE (1998) Do molecular markers predict survival in non-small-cell lung cancer? Am J Respir Crit Care Med 157: 1093 - 1097

Grossi F, Loprevite M, Chiaramondia M, Ceppa P, Pera C, Ratto GB, Serrano J, Ferrara GB, Costa R, Boni L, Ardizzoni A (2003) Prognostic significance of K-ras, p53, bcl-2, PCNA, CD34 in radically resected nonsmall cell lung cancers. Eur J Cancer 39: 1242 - 1250

Harada M, Dosaka-Akita H, Miyamoto H, Kuzumaki N, Kawakami Y (1992) Prognostic significance of the expression of ras oncogene product in non-small cell lung cancer. Cancer 69: 72-77

Hommura F, Dosaka-Akita H, Mishina T, Nishi M, Kojima T, Hiroumi H, Ogura S, Shimizu M, Katoh H, Kawakami Y (2000) Prognostic significance of p27KIP1 protein and ki-67 growth fraction in non-small cell lung cancers. Clin Cancer Res 6: 4073-4081

Huang CL, Taki T, Adachi M, Konishi T, Higashiyama M, Kinoshita M, Hadama T, Miyake M (1998) Mutations of p53 and K-ras genes as prognostic factors for non-small cell lung cancer. Int J Oncol 12: 553-563

Huncharek M, Muscat J, Geschwind JF (1999) K-ras oncogene mutation as a prognostic marker in non-small cell lung cancer: a combined analysis of 881 cases. Carcinogenesis 20: $1507-1510$

Kang YH, Kim KS, Yu YK, Lim SC, Kim YC, Park KO (2001) The relationship between microvessel count and the expression of vascular endothelial growth factor, p53, and K-ras in non-small cell lung cancer. J Korean Med Sci 16: 417-423

Kanters SD, Lammers JW, Voest EE (1995) Molecular and biological factores in the prognosis of non-small cell lung cancer. Eur Respir J 8: $1389-1397$

Kashii T, Mizushima Y, Lima CE, Noto H, Sato H, Saito H, Kusajima Y, Kitagawa M, Yamamoto K, Kobayashi M (1995) Studies on clinicopathological features of lung cancer patients with K-ras/p53 gene alterations: comparison between younger and older groups. Oncology 52: 219-225

Keohavong P, DeMichele MA, Melacrinos AC, Landreneau RJ, Weyant RJ, Siegfried JM (1996) Detection of K-ras mutations in lung carcinomas: relationship to prognosis. Clin Cancer Res 2: 411-418

Keohavong P, Zhu D, Melacrinos AC, DeMichele MA, Weyant RJ, Luketich JD, Testa JR, Fedder M, Siegfried JM (1997) Detection of low-fraction Kras mutations in primary lung tumors using a sensitive method. Int Cancer 74: $162-170$

Kern JA, Slebos RJ, Top B, Rodenhuis S, Lager D, Robinson RA, Weiner D, Schwartz DA (1994) C-erbB-2 expression and codon 12 K-ras mutation both predict shortened survival for patients with pulmonary adenocarcinomas. J Clin Invest 93: 516-520

Kim YC, Park KO, Kern JA, Park CS, Lim SC, Jang AS, Yang JB (1998) The interactive effect of Ras, HER2, P53 and Bcl-2 expression in predicting the survival of non-small cell lung cancer patients. Lung Cancer 22: $181-190$

Komiya T, Hosono Y, Hirashima T, Masuda N, Yasumitsu T, Nakagawa K, Kikui M, Ohno A, Fukuoka M, Kawase I (1997) p21 expression as a predictor for favorable prognosis in squamous cell carcinoma of the lung. Clin Cancer Res 3: 1831-1835

Konishi T, Huang CL, Adachi M, Taki T, Inufusa H, Kodama K, Kohno N, Miyake M (2000) The K-ras gene regulates vascular endothelial growth factor gene expression in non-small cell lung cancers. Int J Oncol 16: $501-511$

Kwiatkowski DJ, Harpole Jr DH, Godleski J, Herndon JE, Shieh DB, Richards W, Blanco R, Xu HJ, Strauss GM, Sugarbaker DJ (1998) Molecular pathologic substaging in 244 stage I non-small-cell lung cancer patients: clinical implications. J Clin Oncol 16: 2468-2477

Li ZH, Zheng J, Weiss LM, Shibata D (1994) c-k-ras and p53 mutations occur very early in adenocarcinoma of the lung. Am J Pathol 144: 303-309

Martin B, Paesmans M, Berghmans T, Branle F, Ghisdal L, Mascaux C Meert AP, Steels E, Vallot F, Verdebout JM, Lafitte JJ, Sculier JP (2003) Role of Bcl-2 as a prognostic factor for survival in lung cancer: a systematic review of the literature with meta-analysis. $\mathrm{Br}$ J Cancer 89: $55-64$

Meert AP, Martin B, Delmotte P, Berghmans T, Lafitte JJ, Mascaux C, Paesmans M, Steels E, Verdebout JM, Sculier JP (2002a) The role of EGF$\mathrm{R}$ expression on patient survival in lung cancer: a systematic review with meta-analysis. Eur Respir J 20: 975-981

Meert AP, Martin B, Paesmans M, Berghmans T, Mascaux C, Verdebout JM, Delmotte P, Lafitte JJ, Sculier JP (2003) The role of HER-2/neu expression on the survival of patients with lung cancer: a systematic review of the literature. Br J Cancer 89: 959-965

Meert AP, Paesmans M, Martin B, Delmotte P, Berghmans T, Verdebout JM, Lafitte JJ, Mascaux C, Sculier JP (2002b) The role of microvessel 
density on the survival of patients with lung cancer: a systematic review of the literature with meta-analysis. Br J Cancer 87: 694-701

Minamoto T, Mai M, Ronai Z (2000) K-ras mutation: early detection in molecular diagnosis and risk assessment of colorectal, pancreas, and lung cancers - a review. Cancer Detect Prev 24: 1-12

Mitsudomi T, Steinberg SM, Oie HK, Mulshine JL, Phelps R, Viallet J, Pass H, Minna JD, Gazdar AF (1991) ras gene mutations in non-small cell lung cancers are associated with shortened survival irrespective of treatment intent. Cancer Res 51: 4999-5002

Miyake M, Adachi M, Huang C, Higashiyama M, Kodama K, Taki T (1999) A novel molecular staging protocol for non-small cell lung cancer. Oncogene 18: $2397-2404$

Miyamoto H, Harada M, Isobe H, Akita HD, Haneda H, Yamaguchi E, Kuzumaki N, Kawakami Y (1991) Prognostic value of nuclear DNA content and expression of the ras oncogene product in lung cancer. Cancer Res 51: 6346-6350

Moldvay J, Scheid P, Wild P, Nabil K, Siat J, Borrelly J, Marie B, Farre G, Labib T, Pottier G, Sesboue R, Bronner C, Vignaud JM, Martinet Y, Martinet N (2000) Predictive survival markers in patients with surgically resected non-small cell lung carcinoma. Clin Cancer Res 6: 1125-1134

Nelson HH, Christiani DC, Mark EJ, Wiencke JK, Wain JC, Kelsey KT (1999) Implications and prognostic value of K-ras mutation for earlystage lung cancer in women. J Natl Cancer Inst 91: 2032-2038

Nemunaitis J, Klemow S, Tong A, Courtney A, Johnston W, Mack M, Taylor W, Solano M, Stone M, Mallams J, Mues G (1998) Prognostic value of Kras mutations, ras oncoprotein, and c-erb B-2 oncoprotein expression in adenocarcinoma of the lung. Am J Clin Oncol 21: 155-160

Paesmans M, Sculier J-P, Lecomtre J, Thiriaux J, Libert P, Sergysels R, Bureau G, Dabouis G, Van Custem O, Mommen P, Ninane V, Klastersky J, for the European Lung Cancer Working Party (2000) Prognostic factors in patients with small cell lung cancer: analysis of a series of 763 patients included in four consecutive prospective trials and with a minimal 5-year follow-up duration. Cancer 89: 523-533

Paesmans M, Sculier J-P, Libert P, Bureau G, Dabouis G, Thiriaux J, Michel J, Van Custem O, Sergysels R, Mommen P (1995) Prognostic factors for survival in advanced non-small cell lung cancer: univariate and multivariate analyses including recursive partitioning and amalgamation algorithms in 1052 patients. J Clin Oncol 13: 1221-1230

Parmar MK, Torri V, Stewart L (1998) Extracting summary statistics to perform meta-analyses of the published literature for survival endpoints. Stat Med 17: 2815-2834

Pifarré A, Rosell R, Monzo M, De Anta JM, Moreno I, Sanchez JJ, Ariza A, Mate JL, Martinez E, Sanchez M (1997) Prognostic value of replication errors on chromosomes $2 \mathrm{p}$ and $3 \mathrm{p}$ in non-small-cell lung cancer. $\mathrm{Br} J$ Cancer 75: $184-189$

Ramirez JL, Sarries C, de Castro PL, Roig B, Queralt C, Escuin D, de Aguirre I, Sanchez JM, Manzano JL, Margeli M, Sanchez JJ, Astudillo J, Taron M, Rosell R (2003) Methylation patterns and K-ras mutations in tumor and paired serum of resected non-small-cell lung cancer patients. Cancer Lett 193: $207-216$

Rodenhuis S (1992) ras and human tumors. Semin Cancer Biol 3: 241-247 Rodenhuis S, Boerrigter L, Top B, Slebos RJ, Mooi WJ, van't Veer L, van Zandwijk N (1997) Mutational activation of the K-ras oncogene and the effect of chemotherapy in advanced adenocarcinoma of the lung: a prospective study. J Clin Oncol 15: 285-291

Rodenhuis S, Slebos RJ (1990) The ras oncogenes in human lung cancer. Am Rev Respir Dis 142: S27-S30

Rodenhuis S, Slebos RJ, Boot AJ, Evers SG, Mooi WJ, Wagenaar SS, van Bodegom PC, Bos JL (1988) Incidence and possible clinical significance of K-ras oncogene activation in adenocarcinoma of the human lung. Cancer Res 48: $5738-5741$

Rosell R, Li S, Skacel Z, Mate JL, Maestre J, Canela M, Tolosa E, Armengol P, Barnadas A, Ariza A (1993) Prognostic impact of mutated K-ras gene in surgically resected non-small cell lung cancer patients. Oncogene 8: $2407-2412$

Rosell R, Molina F, Moreno I, Martinez E, Pifarre A, Font A, Li S, Skacel Z, Gomez-Codina J, Camps C (1995a) Mutated K-ras gene analysis in a randomized trial of preoperative chemotherapy plus surgery $v s$ surgery in stage IIIA non-small cell lung cancer. Lung Cancer 12(Suppl 1): S59-S70
Rosell R, Monzo M, Molina F, Martinez E, Pifarre A, Moreno I, Mate JL, De Anta JM, Sanchez M, Font A (1995b) K-ras genotypes and prognosis in non-small-cell lung cancer. Ann Oncol 6(Suppl 3): S15-S20

Rosell R, Monzo M, Pifarre A, Ariza A, Sanchez JJ, Moreno I, Maurel J, Lopez MP, Abad A, De Anta JM (1996) Molecular staging of non-small cell lung cancer according to K-ras genotypes. Clin Cancer Res 2: $1083-1086$

Rosell R, Pifarre A, Monzo M, Astudillo J, Lopez-Cabrerizo MP, Calvo R, Moreno I, Sanchez-Cespedes M, Font A, Navas-Palacios JJ (1997) Reduced survival in patients with stage-I non-small-cell lung cancer associated with DNA-replication errors. Int J Cancer 74: 330-334

Schiller JH, Adak S, Feins RH, Keller SM, Fry WA, Livingston RB, Hammond ME, Wolf B, Sabatini L, Jett J, Kohman L, Johnson DH (2001) Lack of prognostic significance of p53 and K-ras mutations in primary resected non-small-cell lung cancer on E4592: a Laboratory Ancillary Study on an Eastern Cooperative Oncology Group Prospective Randomized Trial of Postoperative Adjuvant Therapy. J Clin Oncol 19: 448 - 457

Schneider PM, Praeuer HW, Stoeltzing O, Boehm J, Manning J, Metzger R, Fink U, Wegerer S, Hoelscher AH, Roth JA (2000) Multiple molecular marker testing (p53, C-Ki-ras, c-erbB-2) improves estimation of prognosis in potentially curative resected non-small cell lung cancer. Br J Cancer 83: 473-479

Shoji T, Tanaka F, Takata T, Yanagihara K, Otake Y, Hanaoka N, Miyahara R, Nakagawa T, Kawano Y, Ishikawa S, Katakura H, Wada H (2002) Clinical significance of p21 expression in non-small-cell lung cancer. $J$ Clin Oncol 20: 3865-3871

Siegfried JM, Gillespie AT, Mera R, Casey TJ, Keohavong P, Testa JR, Hunt JD (1997) Prognostic value of specific KRAS mutations in lung adenocarcinomas. Cancer Epidemiol Biomarkers Prev 6: 841-847

Silini EM, Bosi F, Pellegata NS, Volpato G, Romano A, Nazari S, Tinelli C, Ranzani GN, Solcia E, Fiocca R (1994) K-ras gene mutations: an unfavorable prognostic marker in stage I lung adenocarcinoma. Virchows Arch 424: 367 -373

Slebos RJ, Kibbelaar RE, Dalesio O, Kooistra A, Stam J, Meijer CJ, Wagenaar SS, Vanderschueren RG, van Zandwijk N, Mooi WJ (1990) $\mathrm{K}$-ras oncogene activation as a prognostic marker in adenocarcinoma of the lung. $N$ Engl J Med 323: $561-565$

Steels E, Paesmans M, Berghmans T, Branle F, Burniat A, Ghisdal L, Lafitte J-J, Lemaitre F, Mascaux C, Meert A-P, Vallot F, Sculier J-P (2001) Role of p53 on the survival of patients with lung cancer as assessed by a systematic review of the literature. Eur Respir J 18: 705-719

Strauss GM (1997) Prognostic markers in resectable non-small cell lung cancer. Hematol Oncol Clin N Am 11: 409-434

Sugio K, Ishida T, Yokoyama H, Inoue T, Sugimachi K, Sasazuki T (1992) ras gene mutations as a prognostic marker in adenocarcinoma of the human lung without lymph node metastasis. Cancer Res 52: 2903-2906

Tomizawa Y, Kohno T, Kondo H, Otsuka A, Nishioka M, Niki T, Yamada T, Maeshima A, Yoshimura K, Saito R, Minna JD, Yokota J (2002) Clinicopathological significance of epigenetic inactivation of RASSF1A at 3p21.3 in stage I lung adenocarcinoma. Clin Cancer Res 8: $2362-2368$

Visscher DW, Yadrandji S, Tabaczka P, Kraut M, Sarkar FH (1997) Clinicopathologic analysis of k-ras, p53, and ERBB-2 gene alterations in pulmonary adenocarcinoma. Diagn Mol Pathol 6: 64-69

Volm M, Drings P, Mattern J, Wodrich W (1993) Prognostic value of oncoproteins for the survival of patients with non-small cell lung carcinomas. Int J Oncol 2: 767-772

Volm M, Koomagi R, Mattern J, Efferth T (2002) Expression profile of genes in non-small cell lung carcinomas from long-term surviving patients. Clin Cancer Res 8: $1843-1848$

Wang YC, Lee HS, Chen SK, Yang SC, Chen CY (1998) Analysis of K-ras gene mutations in lung carcinomas: correlation with gender, histological subtypes, and clinical outcome. J Cancer Res Clin Oncol 124: 517-522

Westra WH, Slebos RJ, Offerhaus GJ, Goodman SN, Evers SG, Kensler TW, Askin FB, Rodenhuis S, Hruban RH (1993) K-ras oncogene activation in lung adenocarcinomas from former smokers. Evidence that K-ras mutations are an early and irreversible event in the development of adenocarcinoma of the lung. Cancer 72: $432-438$

Yusuf S, Peto R, Lewis J, Collins R, Sleight P (1985) Blockade during and after myocardial infarction: an overview of the randomized trials. Prog Cardiovasc Dis 27: $335-371$ 